\title{
Deep Roads: Innovative Solutions to alleviate traffic Jam and Pollution Problems
}

\author{
Saffa Riffat* and Yijun Yuan \\ University of Nottingham, UK
}

*Corresponding author: Saffa Riffat, University of Nottingham, UK.

Received Date: June 21, 2019

Published Date: June 26, 2019

\section{Mini Review}

Problems caused by climate change, environmental pollution, population growth, lack of resources and limited land areas for agriculture and human habitation will require a variety of innovative solutions to be rapidly developed and implemented in the coming decades. The number of vehicles on roads worldwide is projected to reach the two billion mark by 2040 and the UK Department of Transport predicts that the traffic volumes to increase by $55 \%$ between now and then. Transport accounts for about a quarter of the UK's greenhouse emissions which will create massive challenges for road transport systems and the environment. In addition, the current transportation systems are affected by weather conditions such as rain, snow and wind, which decreases safety, slows traffic flow and increase energy use and pollution level. Roads also require a very large proportion of land in built up areas and create, with the associated traffic jams and noise pollution, significantly reduced quality of life. Creation of 'Deep Roads' will alleviate many of these issues at minimal costs and effectively increase the habitable area of built-up areas. Professor Riffat said 'We have come up with unique solutions to address traffic jam and vehicle pollution problems'. The concept of Deep Roads is to create several meter-deep channels below the surface level in which the road would be built. These channeled roads, both in cities and highways, has numerous environmental advantages and helps to alleviate congestion with the ever-growing vehicle use. Unlike tunnels or elevated city roads with flyover roads, both of which can be difficult and expensive to build, particularly over large distances, Deep Road can be created by removing the soil to form an open channel at minimal cost. The channel is then covered by a prefabricated structural roof made off site. The Deep Road will allow vehicle movements at two levels, with the roof supporting a surface road for light transport, public transport, or open spaces for pedestrians and cycle paths. The space in cities and congested areas once dedicated to surface roads could then be used to create more live able areas, free from noise, pollution and congestion. Pedestrians and cycles would enjoy greatly improved safety with vehicles mostly segregated to the Deep Road system. Deep Roads are particularly attractive for use in large cities such as London, New York and Shanghai since it is not possible to widen the roads due the proximity of surrounding buildings. Deep Roads would also be play important role in future fully electric vehicle infrastructure, where the vehicles electric propulsion is clean, yet as much as $50 \%$ of the particulate pollution is generated by tyre degradation. These particles can be captured and treated using Deep Roads (Figure 1).

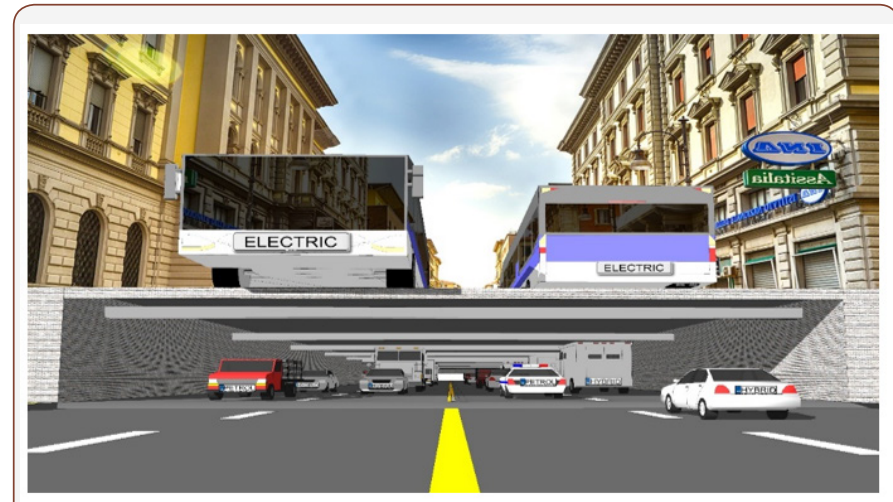

Figure 1: The Concept of Deep Roads in Cities.

Deep Roads could be created for new highways using advanced digging equipment and the soil removed used for road construction and covering. Conventional highways use soil for the road sublayers which is dug out and transported from different sites. The digging out and transportation of soil for the sublayers are both expensive and energy intensive. In addition. The creation of conventional wide highways usually requires the use of agriculture land and often the demolition of existing buildings. Deep Roads would not be affected by poor weather conditions, providing a more controlled environment, thus creating a smarter and safer transport than 
conventional highways and also improved traffic flow. This would lead to reduced energy consumption from vehicles and increased road safety. Exhaust gases and particles (CO2, NOx, PM10, etc.) from vehicles would be captured in the Deep Road systems by collection using duct systems. The gases are then passed to a purification/ filtration unit and released at periodic locations above ground to diffuse into the air. The $\mathrm{CO} 2$ from the purifier could be transferred to nearby greenhouses or Deep Farms for food production (http:// www.environmenttimes.co.uk/news/item/753-concept-of-deepfarms-underneath-cities imagined). The air purification system could effectively capture particulate pollutants such as PM2.5 and PM10 and these can be removed using an innovative aerogel filtration system. Professor Riffat added 'We will need radical changes in our transport systems as the number of cars worldwide is set to double by 2040' (Figures $2 \& 3$ ).

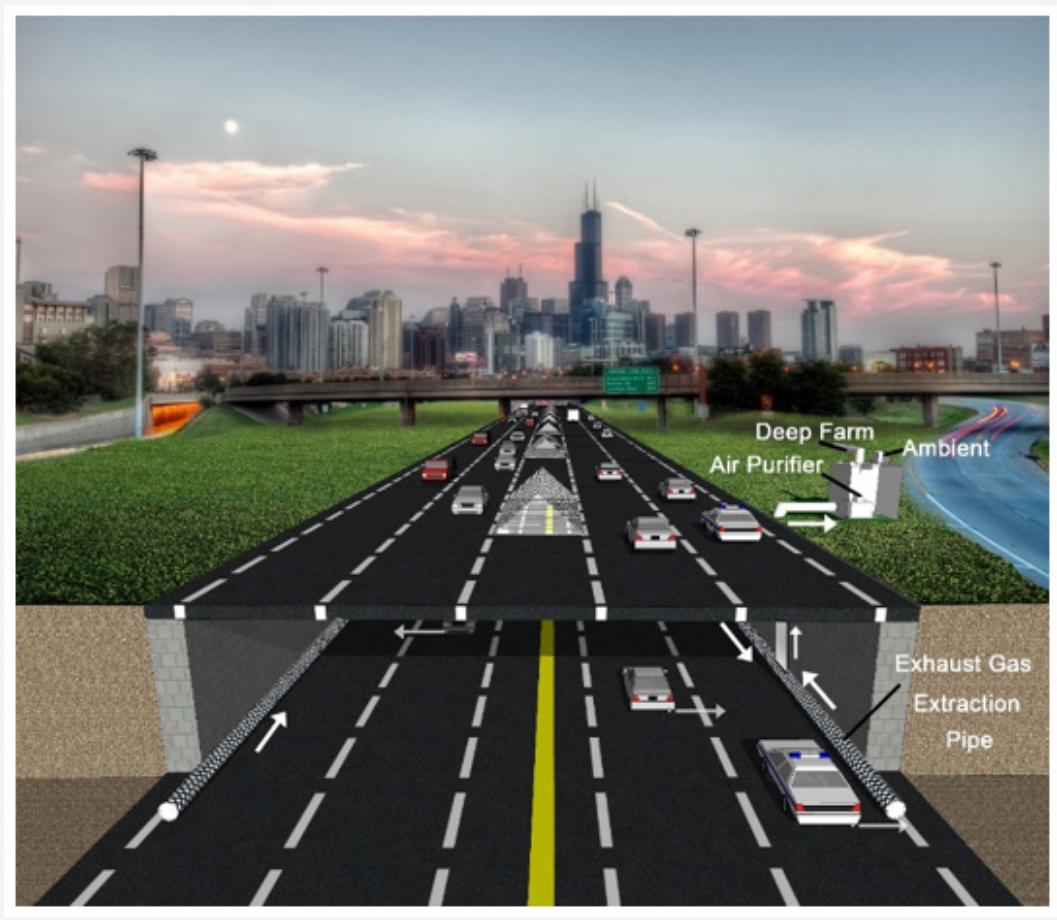

Figure 2: Deep Road Concept for Highways.

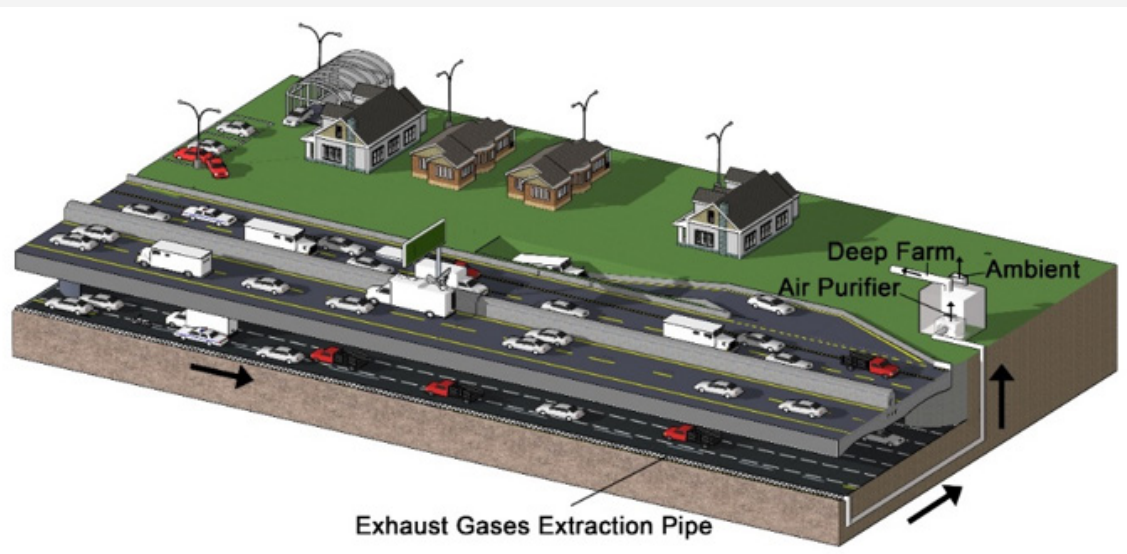

Figure 3: Section View of the Deep Road for Highways.

Deep Roads could incorporate sky daylighting devices to minimize the use of artificial light and also enhance the environment. In addition, Deep Roads could be fitted with emergency access areas and bays for broken down vehicles.

\section{The Main Benefits of Deep Roads Include}

\section{New highways}

The cost of construction of Deep Roads for new highways using advanced digging equipment would be cost effective.
Unlike conventional highways Deep Roads are not required the transportation of expensive sublayer soil from other sites.

\section{City roads}

The widening of roads in cities is expensive due to the high land cost and also in many cases it is not easy to carry out such modifications due to the proximity of surrounding buildings. Flyover roads are expensive to construct and also not esthetically appealing. Underground tunnels are very expensive to build 
especially in poor geological conditions. A typical cost of a tunnel could be as high as $£ 30$ million per $\mathrm{km}$. The estimated cost of a Deep Road is about $1 / 10$ of underground tunnels.

\section{Fast construction}

Digging 3-5 m deep channels for 'Deep Roads' could be easily implemented using advanced digging equipment with multiple working sites simultaneously. The prefabricated roofs could be completed in advance off site.

\section{Congestions/safety}

Deep Roads with at least two-layer roads in cities are not only double the road capacity but also avoid the use of cross junction traffic control lights. The traffic in Deep Roads is not affected by weather conditions such as rain and snow and would be safer than surface roads.

\section{Pollution control}

For city roads, surface roads would be mainly used for electric buses for public transport and lower road layer for conventional petrol and diesel vehicles. The harmful vehicle exhaust gases can be removed and treated using air purification systems. Deep Roads would be important for future fully electric vehicle infrastructure as $50 \%$ of the particulate pollution is generated by tyre degradation can be removed and treated using the air purification/filtration systems.

\section{Acknowledgment}

None.

\section{Conflict of Interest}

No conflict of interest. 